\title{
What is on the horizon for science, technology and education in 2015?
}

What developments or breakthroughs might we expect in science, technology and education in 2015? Scientists and scholars have a well-honed knowledge of the changes that will take place in their own fields, but what of the broader picture, and the developments that could well take longer than the public might be anticipating? Here is a sampling of just four areas of interest for 2015 .

Over the past 2 years, the South African component of the Square Kilometre Array (SKA), its 64-dish MeerKAT element and MeerKAT's seven-dish KAT prototype have received justifiable and praiseworthy press coverage. The SKA was awarded jointly to South Africa (and its African collaborators) and Australia in 2012, and the design plans for the SKA are now well underway. In the meantime, considerable progress has been made in developing KAT-7 and MeerKAT. But ask any astrophysics postgraduate when they hope to start analysing data from the complex project, and you will probably receive an ambivalent and somewhat anguished reply: 'Maybe by the end of 2015? - at the earliest'. For although KAT-7 has been commissioned and is delivering images, MeerKAT was formally launched only in March last year, and the larger components of the SKA will be built between 2018 and 2020. So while some research work is being undertaken, the primary tasks are now those of the engineers and advisory scientists. What then might be expected in 2015? Certainly, progress on the design of the SKA, continuing development work on MeerKAT and, perhaps, the first serious streams of hard data towards the end of this year from the first 16 dishes. Dr Rob Davies has demanding tasks ahead of him as the project's Director Designate.

At both school and university levels, education in South Africa faces problems of overcrowding and levels of demand that go beyond existing capacities. In the school system, underqualified teachers add considerably to the problem. At university level, information and communication technologies have long been implemented and considerable progress has been made. In Gauteng, Panyaza Lesufi - the MEC for Education - has decided that the use of virtual learning techniques at school level will not only make the most effective use of the province's best teachers, but will also contribute to the erosion of racial differentiation in public schools.

Pairs of schools will be 'twinned' over the next 6 months using smart technology with Wi-Fi, interactive boards and tablets for pupils, as the chalk board gives way to the talk board. Technology aside, teachers in the twinned schools will be provided with the support they will need to ensure that the venture will have the best chance of success. Boitumelong Secondary in Tembisa and Kempton Park High will be the first schools to be 'merged virtually', and they will be followed by Sandown High and Alexandra High in Johannesburg, Hoërskoel Waterkloof and Mamelodi Secondary in Pretoria, and Hoërskool Noordheuwel and Kagiso Secondary in Krugersdorp. The province has made ZAR2 billion available for the project, and 80000 tablets (tagged to limit theft) have been delivered. What might we hope will happen in 2015? A project so successful that it is taken to scale across the country would be an encouraging development.

Its operations suspended for 2 years (2013-2014) for maintenance and major upgrades, CERN's Large Hadron Collider (LHC) will start operating at 13 tera-electron volts (13 TeV), up from the $7 \mathrm{TeV}$ and then $8 \mathrm{TeV}$ at which it previously functioned. Since the shutdown, engineers and technicians have been repairing and strengthening the $27-\mathrm{km}$ accelerator in preparation for its restart. Some 18 of the 1232 dipole magnets that steer particle beams around the accelerator have been replaced, and more than 10000 electrical interconnections between the magnets have been strengthened. The LHC's vacuum, cryogenics and electronics systems have also been consolidated.

The collision energy of $13 \mathrm{TeV}$ is a significant increase compared with the initial 3-year LHC operation. In addition, in the run that starts this year, bunches of protons in the accelerator will collide at briefer intervals - 25 nanoseconds (ns) instead of $50 \mathrm{~ns}$ - and the beams will be more tightly focused. All these factors are intended to optimise the delivery of particle collisions for physics research. With collisions at energies never reached in a particle accelerator before, the LHC will open a new window for discovery, including the possibility of solving the riddle of dark matter, finding evidence of a far-reaching cosmic concept known as 'supersymmetry' (the idea that for every matter particle there is also a corresponding force-carrying particle), and even discovering signs of extra hidden dimensions that help explain the mystery of gravity. All this will require not one but several Higgs bosons, providing a new quarry for the LHC scientists to pursue. Some scientists are sceptical, believing that this phase will not achieve any of these desiderata if, in fact, anything at all. This is, perhaps, the nature of the (currently) outer limits of physics and the LHC itself. Then again, the Higgs boson has been found to exist, so who knows what to expect once the LHC starts up again? Perhaps a new understanding of aspects of the universe?

In an entirely different realm, there is a story that reads, initially, a little like an adventure book for teenagers, starting with a Facebook job advertisement for individuals with 'excellent excavation skills' and a master's or PhD degree in areas of palaeoanthropology, who also are skinny, preferably small and fit, who have climbing experience, and who are not claustrophobic. The adventure book phase ended with six young women being hired to work on the project that became Rising Star. The story for teenagers ends with 'science tents', generators, lights, cameras, computers, funds from National Geographic, and 'somewhat larger, more senior' palaeoanthropologists installed at ground level while the six went underground. In 3 weeks, the underground team brought 1200 fossils to the surface - including, it is believed, more than 12 complete individuals. In the Leader of the next issue, Dr Patrick Randolph-Quinney, a member of the Rising Star team, will share background information about the project and, in the months that follow, research findings from the project will be published in Nature. What might we expect as Nature begins to publish early results from Rising Star? Another branch of the early hominids? A new piece in the jigsaw puzzle of evolution and the emergence of Homo sapiens sapiens? An explanation as to why so many fossils, and individuals, ended in so remarkable a concentration? The papers in Nature will surely reveal some of the answers in the course of 2015.

Few though they are, these examples suggest that 2015 will be a year filled with the promise of stimulating developments and discoveries. These will assuredly keep readers of the SAJS engaged and looking out for even more to follow in 2016.

HOW TO CITE: Butler-Adam J. What is on the horizon for science, technology and education in 2015? S Afr J Sci. 2015;111(1/2), Art. \#a0096, 1 page. http://dx.doi.org/10.17159/sajs.2015/a0096

(c) 2015. The Author(s). Published under a Creative Commons Attribution Licence. 